\title{
PO-ÉTICAS. O CULTIVO DA LÍNGUA COMO IDENTIDADE EM 5 PROPOSIÇÓES
}

\section{PO-ETHICS. UNDERSTANDING LANGUAGE AS IDENTITY IN 5 PROPOSITIONS}

\author{
Hugo Monteiro \\ Universidade do Porto, Porto, Portugal
}

\begin{abstract}
Resumo: Este texto parte de um único verso de A Mensagem, de Fernando Pessoa, para questionar o conceito de identidade e de cultura a partir da experiência poética. Convocando a interseção entre filosofia e poesia, faz-se alusão ao "more geometrico" de Espinosa, mas recorrendo preferencialmente a Deleuze, a Blanchot ou a Eduardo Lourenço como autores que suscetibilizam tanto um cruzamento entre filosofia e literatura quanto uma outra noçáo de identidade e de cultura.
\end{abstract}

Palavras-chave: Pessoa; Identidade; Cultura; Escrita.

Abstract: This essay starts from a single line of Fernando Pessoa's A Mensagem, in order to question the concepts of identity and culture from a poetical experience point of view. Engaging the intersection between philosophy and poetry, Spinoza's "more geometrico" is underlined, mainly in its readings by Gilles Deleuze, Maurice Blanchot or Eduardo Lourenço. These approaches allow us to question the notions of identity and culture, mobilizing at the same time the crossways of literature and philosophy.

Keywords: Pessoa; Identity; Culture; Writing.

\section{Abertura: do desejo de território ao território do desejo}

A presente reflexão, assumidamente não convencional quanto à estrutura e sustentação, poderia ser apenas uma leitura, mais ou menos argumentada, de $O$ mostrengo, célebre poema de A mensagem (1967), de Fernando Pessoa. Mas não é. E não é por vários motivos, ainda que não abdique nem de eleger este poema como uma espécie de "cena primitiva", nem de colher um certo ímpeto nas suas águas revoltas e possibilitadoras de revolta. Este escrito acolhe o poema pessoano como um mote para pensar o desejo de viagem como matriz e como experiência po-ética - com o cultivo da língua como espaço do pensamento. Entregamo-nos então a este poema, incluso na segunda parte de A Mensagem, "Mar Português" ou, mais propriamente, à ressonância identitária de um único verso do poema: "aqui ao leme sou mais do que eu”. Sublinhe-se: ressonância identitária... 
$\mathrm{O} \mathrm{Eu}$, como elemento pronominal marcando um Ego, excede-se, poeticamente, por sobre as águas e ao leme, de tal maneira que aqui, nesse leme, eu é mais do que Eu. Eu, é, eventualmente, um Outro, retomando o conhecido lema modernista de Rimbaud (1992, p. 233): "Eu é um outro"; "aqui ao leme sou mais do que eu". Na viagem, na experiência de viagem que poderia ser, também, a viagem ensaiada entre literatura e filosofia, o Eu excede-se. Mais propriamente, o Eu encontra-se com a excedência que é, por hipótese, a sua condiçáa, onde a água navegada é o elemento de todo o intermédio, de tal modo que, entre o Eu e o Outro, um mar se intromete, com a fluidez necessária para espaçar e interromper o Eu como coincidência a si.

Mesmo quando um desejo de território motiva uma intenção, numa volição coletiva - "sou um povo que quer o mar que é teu" -, a travessia converte um desejo de território em território de desejo. Pelo que o desejo se torna centro de uma narrativa identitária, que o sonho impossível de um alcance marítimo reflete como uma espécie de conatus ${ }^{1}$, uma espécie de "acentuaçáo do futuro" (MARTINS, 2008, p. 457) falseando a presença de uma pretensa concreção nacional, estranha a toda a poesia que mereça o seu nome. Na água e por sobre as águas, lembrando que a água é território do informe (PITA, 2007), reclama-se a reinvenção de um desenho identitário, com a poesia como cultivo e única expressão.

A mesma confessada não convencionalidade deste texto leva-nos, também, à interseção do par filosofia/literatura como possível esboço de um problema de método. Nesse problema, de modo heterodoxo, evocaremos longinquamente o pensamento de Espinosa, insigne precursor de um método onde a força do desejo (no nosso texto, a força do poema) não se subjuga ao desejo de força (como expressão moderna e cartesiana de método).

\section{Um Método em dois andamentos}

Tratar-se-á, neste ensaio, de uma certa sedução do método. O mesmo é admitir, por concomitância, que o método se faz revestir de uma espécie de sedução interna. A sua estratégia é essa e é, em si mesma, pouco metódica, no sentido cartesiano da palavra: reclama uma entrega, pelo que, mesmo que sem querer, se dá ao magnetismo de uma certa incerteza. O método

\footnotetext{
${ }^{1}$ Deleuze, no curso de uma das suas excecionais leituras de Espinosa, sublinha a inseparabilidade deste conceito central espinosiano de um "poder de se ser afetado", envolvendo-se totalmente este poder pelos efeitos de suas afeçóes (2003, p. 134).
} 
esconde a paixão implícita, denunciada na energia com que se alcança a mão que nos sustenta o caminho. A máo volúvel de Beatriz, mão invisível na vertigem metodológica, é tão norteadora quanto exigente. Ela indica o caminho, mas nem sequer é linear nessa indicação.

Filosofia. E literatura. Na conjugação dos dois termos, em si mesmos, o método e a paixão. Conjugados, o método da paixão e a paixão como método. Mas, de repente, esta conjugação abre-se para a primeira dissonância entre paixão e método; como tal, o inicial ímpeto para a ultrapassagem de uma disjunção tradicional, instituída e instituinte, entre Filosofia e Literatura. Estranhar-se-á, porventura, a vizinhança liminar entre esses dois mundos, a dança entre subtração e atração no corpus desses dois discursos.

\subsection{Primeiro andamento}

Da Ética, de Espinosa, diz Deleuze o seguinte:

À primeira leitura, a Ética pode parecer um longo movimento contínuo, que vai quase em linha recta, de uma potência e serenidade incomparáveis, que passa e repassa pelas definiçôes, axiomas, postulados, proposiçōes, demonstraçóes, corolários e escólios, arrastando o todo em seu curso grandioso (ESPINOSA, 1997, p. 156).

Leitor admirativo de Espinosa, de quem guarda não apenas a "disciplina do conceito" (1991, p. 49), mas, igualmente, o ritmo descontínuo da "afeçáo" e do "percepto" (1997, p. 156-157), Deleuze transporta - herdando, na melhor tradição do herdeiro - uma certa pulsão fragmentadora de cursos e de percursos no fio do pensamento. Também ele errante ${ }^{2}$, também ele bolinando num imaginário de infinitas conexôes, Deleuze ilustra um desejo processual $^{3}$ reclamado à experiência da leitura e à leitura como experiência. De toda a leitura - da literatura à filosofia - votada a contrariar a tal domesticaçáo retilínea, linear, da qual Maurice Blanchot denunciou a mono-tonia (BLANCHOT, 2010); leitura que é, antes e na voragem da navegação, "o Sim silencioso que está no centro de toda a tempestade” (BLANCHOT, 1998, p. 259).

\footnotetext{
${ }^{2}$ Reconhecido afastamento nos modos de errância que Derrida, um outro pensador errante, reconhece no in memoriam que lhe endereça), onde se saúda a resiliente insistência na "aliança da necessidade com o aleatório, o caos e o intempestivo" (DERRIDA, 2003, p. 238, grifos do autor).

3 “[...] ] desejo não é forma, mas procedimento, processo" (DELEUZE; GUATTARI, 2003, p. 27).
} 
O texto que se segue assume a energia deambulatória da palavra dita, como se de uma definição se tratasse. Esta definição - "debebit intimam essentiam rei explicare" (CARVALHO, 1960, p. 1) -, numa obrigação de intensidade explanatória, não se deixa conter no formalismo cadavérico de um sistema, por ser, ela também, existência além de essência - como a "causa de si” definida por Espinosa ${ }^{4}$. Definimo-nos, pois, procurando definir um movimento de texto e de palavra que não é só, nem essencialmente linear, numa definição que apenas se confina ao more geometrico que a inspira, se essa geometria desobedecer, espaçada e descontinuamente, à arrumação euclidiana. Uma geometria desobediente, pois, atravessando uma geografia insurgente, como um quase correlato ou como um quase corolário: "aqui ao leme sou mais do que eu" (PESSOA, 1997, p. 75) - eu excedido, atravessado pela sua alteridade e nela precedido, cindido e desidentificado; "povo que quer o mar que é teu", adiando nesse desejo a sua definiçáo, pela sobreposse que é o desejo de mar. Imaginários em errância como passo de um primeiro andamento.

\subsection{Segundo andamento}

É que, para bem determinar as coordenadas do "cultivo da língua" com que nos fizemos enquadrar no título, e sublinhando o domínio terreno ao qual tal cultivo nos parece confinar, melhor será tentar estabelecer a ligação entre mar e terra, onda e areia, distância e proximidade - errâncias e ancoragens: Po-éticas - o cultivo da língua como espaço de pensamento. $\mathrm{Na}$ verdade, o propósito ambicioso desta reflexáo encontra-se (isto é, encontranos, na fuga ao registo autonómico da vontade que todo o encontro é) no título que a motiva, no duplo registo de uma ética e de uma poética que nos surgem no caminho, de forma quase táo inexorável e arredia como a figura virulenta do gigante Adamastor. E assim ressoam estes táo comentados versos pessoanos:

\footnotetext{
Três vezes do leme as mãos ergueu,

Três vezes ao leme as reprendeu,

E disse no fim de tremer três vezes:

"Aqui ao leme sou mais do que eu:

Sou um povo que quer o mar que é teu

(PESSOA, 1967, p. 75).
}

\footnotetext{
${ }^{4}$ Espinosa, na sua Ética, Definição I: "Por causa de si entendo aquilo cuja essência envolve a existência; ou por outras palavras, aquilo cuja natureza não pode ser concebida senão como existente" (1960, p. 1-2, grifos do autor).

${ }^{5}$ Poema, Mar Português, de Fernando Pessoa.
} 
Mais do que um sujeito e talvez ainda não um povo, o lugar do leme faz com que um "Eu" se exceda, elevando-se do mesmo de si mesmo: "mais do que um", mais do que "eu". Um destino de errância navegadora afirmase identitariamente, mas, desde logo, dizendo-se como excesso sobre uma identidade, talvez sobre toda a identidade.

Marquemos então, ainda que em velocidade meteórica, o duplo gesto de ruptura de que estes versos poderiam constituir ilustração, senão legenda. Ruptura que, no reduto próprio de todo e qualquer poema, reengendra tempo e espaço, na imensurabilidade deslocalizada que é toda a língua no poema. A acutilância leitora de Eduardo Lourenço assinala justamente o reequacionar de uma certa portugalidade, de uma certa cultura portuguesa, no tempo novo afirmado em A Mensagem, rasurando "todas as nostalgias épicas" para afirmar o devir em "epopeia futura" (LOURENÇO, 2004, p. 162-163). O mar pessoano ultrapassa o passado, até aí guarida de uma identidade construída em torno de um olhar para trás, para troar como "promessa, desafio e dúvida" (LOURENÇO, 2004, p. 165), tendo por azimute a palavra e a experiência poética.

Mas, além do tempo, este poema indicia também uma mais longitudinal reflexáo espacial, possivelmente lembrando o reduto ilimitado e transgressor da palavra poética sobre todo o lugar. Num pressuposto que nos ocupará mais longamente, afirmaremos a necessidade de se apartar espaço de lugar, em nome do poema e tendo em vista uma certa po-ética.

\section{Definiçóes}

I. Como primeiro indício, falaremos de desejo.

II. Nenhum desejo se domestica, nem mesmo aquele que se póe em jogo numa afirmaçáo cultural ou identitária. Ele guarda em si mesmo uma enorme capacidade de fuga - da definição, da identificação, etc -, pelo que a única forma de transportar essa palavra esquiva, essa afeçáo arredia a que chamamos desejo, passará sempre por assumir o excesso, que parece ser a sua única forma de habitar. Levado nessa palavra, é o próprio Eu que se dessitua, que se deslocaliza rumo a um lugar desconhecido que o reclama, que o ameaça e que o póe em perigo, mas portador de uma tentação magnética quase inexorável.

III. Quando se intenta pensar, por exemplo, uma cultura de língua portuguesa sob este signo desejante, a tentaçáo ou o ímpeto da viagem surgenos como uma evidência tangível. E se essa viagem se encontra na energia do 
poema, se ela se reinventa ao bater ondulante de cada sílaba, reclamamos a uma outra língua a legitimidade de uma palavra intraduzível: dépaysement. Um país ausentando-se de si próprio, deslocalizando-se - navio-nação ${ }^{6}-$ para um exterior que excede o seu dizer-se. Como escreve Maurice Blanchot, "não apenas a perda do país, mas uma maneira mais autêntica de residir, de habitar sem hábito" (BLANCHOT, 1969, p. 452), como se o exterior para o qual aponta o poema - "aqui ao leme sou mais do que eu" - fosse um êxodo que o transisse por dentro, "afirmação de uma nova relação com o Exterior” (BLANCHOT, 1969, p. 452). Poderíamos encontrar, nesse espaço de desejo, uma hipótese de leitura, um lugar de reconsideração identitária num Eu que se entrega à sua própria excedência? Uma poética? Uma ética também? Seria legítimo demonstrá-las, senão more geometrico, pelo menos num fio de leitura assumidamente exposto à radiação desejante que sempre assombrou esse gesto espinoseano de ousadia metodológica?

\subsection{Proposição I: $O$ espaço do pensamento não é equivalente ao lugar do pensamento}

\section{Demonstraçáo}

Há que distinguir "espaço" de "lugar", ainda que reconhecendo a permeabilidade (inevitável e necessária) do lugar face ao espaço. Falamos de espaço, não de lugar, marcando distância de um plano geo-político, geo-estratégico, reduto fronteiriço e cartografável ao qual vimos chamando Portugal. Tentaremos então falar a partir de espaço, de um espaço mediado linguisticamente e negociado nos rebordos selvagens de toda a língua, de toda a criaçáo poética. Comecemos, então, por falar de um espaço de errância, por oposiçáo à rigidez topológica de um local; e comecemos por falar do espaço literário, esse, tão marcadamente nítido no modo como a língua portuguesa se torna pensável.

\section{Escólio 1}

As palavras motrizes de Blanchot, em L'espace littéraire, permitemnos uma energia interpretativa considerável no que toca a esta distinção necessária. Ao afirmar que "o escritor não pode coabitar com a obra" (BLANCHOT, 1998, p. 17), Blanchot não consente na certeza enunciativa de um estatuto literário, na categoria estável de uma autoria. Por outro lado,

${ }^{6}$ Cantado por Álvaro de Campos: "Ah o Grande Cais donde partimos em Navios-Naçôes!" (2002, p. 109). 
Blanchot define o leitor como uma espécie de afirmação acolhedora face a um indominável: o leitor dança "com uma companheira invisível" (1998, p. 261). A obra, por sua vez, é, nas suas palavras, "intimidade desfeita da sua própria essência” (1998, p. 307), partilhando o registo insituável já insinuado nas restantes instâncias do espaço literário. Blanchot ensina-nos, talvez como nenhum outro pensador-escritor, a irredutibilidade do lugar face ao espaço, no reduto impossível que é o espaço literário, possibilitando também uma ampla e profunda indagação acerca da "coisa cultural", de um possível registo não posicional, não fronteiriço, não situado porque na língua (Portuguesa?). Como khôra, para Derrida, mais situante do que situada (DERRIDA, 1993, p. 22), isto é, necessariamente esquiva aos mais tradicionais e posicionais discursos sobre "identidade".

\section{Escólio 2}

Agrava-se a questáo identitária, na questáo ética e poética, que nos impulsiona a reencontrar a alteridade enquanto questão, como exposição de limites entre filosofia e literatura.

A dissimetria entre o Outro e o Eu representa um profundo abalo no que foram as interrogaçóes fundamentais da filosofia, mas também no modo como se concebe o pensar da arte, da literatura e, generalizando, de todo o discurso. Estamos no limite do que pode ser dito quando nos confrontamos com a dissimetria da relação com o outro Outro (o Outro absoluto), de tal modo que, quanto mais ele se aproxima, desde a lonjura da sua alteridade, mais se torna evidente a sua incomensurabilidade. Todo o discurso está, pois, posto em cautela, na obrigação ética que dita a não redução do Outro ao alcance económico do Mesmo. Eis também a imbricaçáo profunda entre Ética e Poética, no instante em que o curso do dizer no dis-curso nunca transporta suficientemente o Outro, nunca o apropria - mas não pode, ao mesmo tempo, fazer outra coisa.

\subsection{Proposiçáo II: Nenhuma identidade é una, tal como náo o é nenhuma cultura}

\section{Demonstraçáo}

É abundante a escrita em torno da heteronímia pessoana. O fio da sua história, em sede de estudos pessoanos, não é sintetizável neste espaço, ainda que demonstre, em plena complexidade, a ligação perturbadora entre ser e linguagem. Quer essa linguagem se afirme, de modo heideggereano - como 
casa do ser -, quer essa habitação se formule como reduto do dizer(-se) do poeta $^{7}$, quer ela resulte em excedência do ser, de toda a ontologia e de todo o conceito. A linguagem pluraliza, perturba o reinado do Mesmo e, como tal, fragmenta inexoravelmente o terreno da cultura: "Mesmo quando tudo provém da cultura e acaba por inscrever-se na cultura, o novo, o diferente, o inatual depende sempre de um elemento que não forma propriamente parte da mesma" (PELLEJERO, 2009, p. 110).

\section{Escólio}

A relação entre um poeta como Fernando Pessoa e um ensaísta como Eduardo Lourenço torna-se aqui exemplar. Para Lourenço, desde muito cedo, a leitura de Fernando Pessoa surge como questão de desestruturação. Uma desestruturação plural, tanto na heteronímia, como na resistência que oferece à ambiçáo da planura legente, como na própria complexidade e paradoxalidade de toda a mundividência pessoana. E, assim, o progresso na leitura de Fernando Pessoa revelava, para o ensaísta português:

\footnotetext{
“[...] qualquer coisa que ia além do poético e da ordem estética, impondo-se como uma visão de mundo que punha em causa o discurso dominante em todas as ordens. Pessoa foi, efetivamente, o desarrumador definitivo [...] do discurso cultural português" (GIL; CATROGA, 1996, p. 52, grifos nossos).
}

Em retrospetiva, temos a energia desestruturadora que, já para o jovem e polemizador ensaísta que foi Eduardo Lourenço, constitui um foco de ultrapassagem: seja do instalado equívoco da existência e da centralidade de uma "cultura nacional", de sentido reificador, seja a estagnada ilusão de uma totalizadora "universalidade" da cultura, espécie de rochedo imutável formado devido a "uma má tradução de Aristóteles" (LOURENÇO, 1984, p. 20). Pessoa aparece, assim, em toda a sua ironia, no cenário ostentatório de uma determinada noção de cultura: como o factor de união e de consenso no imaginário cultural português, ele, "com o seu tormento e fragmentação incuráveis” (LOURENÇO, 2004, p. 9). De repente, a pluralidade da língua pessoana ficciona involuntariamente a unidade. Mera ficçáo. Nessa unidade, uma multiplicidade sem pacificação possível reverbera, ressoa, nunca uma só. Como se o mostrengo, esse, "que está no fim do mar", assombrasse, de forma permanente, sem derrota ou vitória, mas em permanente energia disruptiva, uma unidade essencializadora, um desejo de posse, uma

${ }^{7}$ Como escreve Eduardo Lourenço, "O poeta é aquele que escolheu ter um ser através da sua linguagem" (2000, p. 23). 
coincidência consigo mesmo que não bastará mais para definir qualquer identidade.

\subsection{Proposiçáo III: O cultivo da língua é o ter lugar da própria língua}

\section{Demonstraçáo}

A língua não é o lugar, mas funda o lugar. $E$ funda-o em permanência, mostrando como lhe é devida uma permanente refundação. Uma língua não é matéria de soberania, já que não é formulável a partir de um território de pertença. Literária ou filosoficamente, nunca uma língua pertence. Ela nunca está fora do seu acontecer criativo.

\section{Escólio}

Entre filosofia e literatura, de uma margem a outra.

Tendo o espaço literário como referente plural e movediço, Maria Gabriela Llansol pensa a precariedade da noção de contemporaneidade. "Não há contemporâneos - escreve -, mas elos de ausências presentes", logo acrescentando tratar-se de uma "cena infinita - o lugar onde somos figuras" (LLANSOL, 1996, p. 48).

Nunca totalmente presentes, confrontados com o limite fenomenológico inerente ao próprio aparecer, somos irresoluvelmente assimétricos, na sempre adiada deriva da nossa definição. Tal assimetria dita a emergência de uma ética, mas também de uma poética, capaz de transportar essa infinição tão luminosamente testemunhada na "figura" llansoliana. Uma "figura" que, lembremos, excede a personagem em nome de uma impersonificável errância, que apenas a escrita transporta ("Aqui ao leme sou mais do que Eu"). Diremos, então, com Llansol:

A escrita não imagina. A escrita é o que a figura vê, é o que fica depositado nos que a lêem - a nostalgia inexpugnável dos seres que estão por vir. É minha convicção que as figuras (que, no meu texto, são muitas vezes figuras históricas do passado e, enquanto tais, culturalmente identificáveis) vêm do futuro. De que futuro? (LLANSOL, 2000, p. 201).

Afirmando a questão suspensiva de Llansol, de que futuro, senão justamente o prometido numa identidade por dizer ou, mais propriamente, por escrever. Porque a figura é um imaginário em errância. É uma silhueta movente, difusa, arredia a essencialismos ou excessivas concreçôes, preferindo 
dizer-se no ímpeto movente em que escolhe excesso ou por ele é escolhida. Esse excesso é o cultivo da língua. É também, com certeza, inexpugnado território do Outro, que se deseja sem nunca totalmente de deter, sem nunca totalmente se tematizar.

\subsection{Proposiçáo IV: Filosofia como Literatura partilham o problema, de acordo com o qual náo há identidade sem alteridade}

\section{Demonstraçáo}

O Outro nunca é um tema ou uma tese - é intematizável -, o que invalida a tarefa de se falar dele, transportá-lo ou traduzi-lo num discurso que o contenha. Filosofia e Literatura, tanto uma como outra, são instituiçóes discursivas e disciplinares largamente orientadas por esta dimensão de alteridade, obrigadas que estão a traduzi-la, mas ambas a braços com a insuficiência de cada traduçáo concretizada. Todo o discurso deve deslocarse, por isso, da tematização para a invocação: não se falará sobre ele, mas a ele, respeitando (e respondendo, nesse respeito) a distância infinita que o aparta e que o furta à familiaridade. E encontramo-nos, de súbito, com o mar bravio da linguagem no poema.

\section{Escólio}

Daqui se colocam algumas questóes, mantidas longe da finalização de uma resposta única, desdobráveis pela pluralizaçáo de respostas em movimento permanente. Escreve Blanchot:

Como pode dizer-se, expôr-se, apresentar-se a filosofia sem, pelo mesmo caminho, mediante o emprego de certa linguagem, contradizer-se ou hipotecar-se? Não deve o filósofo ser escritor e, então, renunciar à filosofia, sem prejuízo de denunciar a filosofia implícita da escrita? Ou deverá antes aspirar ao ensino, ao domínio, isto é, à aventura da palavra oral não dominada, condescendendo de vez em quando em fazer livros? Como manter a dissimetria, a curvatura do espaço qualificado (sem motivo) de intersubjectivo, a infinitude da fala de infinito? (BLANCHOT, 2010, p. $332)$.

Para Blanchot, é claro que há um problema, uma questão por resolver e provavelmente irresolúvel entre literatura e filosofia, intrometendo-se com decisiva evidência a partilha entre duas margens da palavra "escrita". Trata-se de um problema ético e po-ético, cujo enunciado ameaça rasurar, 
reequacionar, desconstruir toda uma questão identitária. Que aqui, de certa forma, nos ameaça como um fantasma e nos marca indelevelmente, mesmo quando lhe viramos as costas, na interpelação de uma língua portuguesa, de uma cultura portuguesa, de uma cultura de língua portuguesa.

Daí a desconfiança implicada nas seguintes palavras:

Raramente se falou tanto de cultura, de educaçấo cultural, de valores civilizadores. Estudos sérios, como publicaçôes frívolas, servem-se com prazer deste vocabulário sumptuoso e vago. [...] Cultura, civilização são como palavras-passe que indicam caminhos sem termo ou como nomes encantatórios destinados a abrir rumos fechados (BLANCHOT, 2007, p. 49).

Crítica feroz, mas que nos alerta para o registo criador e criativo sem o qual não há cultura e, principalmente, não há cultivo. Aí, onde a língua tem lugar, no instante demasiado antigo para se dar ao presente, demasiado vivo para se conter num passado e demasiado concreto para se remeter a futuro, a língua é o seu próprio ter lugar, identidade permanentemente criada no seu acontecer excessivo. Dar à língua, na língua e na cultura...

\subsection{Proposição V: Toda a identidade é po-ética}

\section{Demonstração}

Provavelmente, nada demonstra esta proposiçáo como a poética e a inscrição de toda a A Mensagem, de Pessoa. Aí, onde nunca logrou constituir-se como "unidade utópica", sendo antes exemplo da fragmentação de um espaço cultural que ela própria pressagia e celebra: apenas uma voz nas vozes que falam o espaço lusófono, tão mais expressiva quanto mais poeticamente conjuga essa pluralidade.

\section{Escólio 1}

Posicionamo-nos aí, onde o termo "identidades", no plural, se propaga de uma maneira espinozeana: uma Ética que, mais do que definida no terreno da moral, espacial ou político - mais do que uma Ética de certa forma rendida ou vergada ao pragmatismo deontológico em que tantas vezes a encerram -, se decide no que Deleuze apelidou por uma espécie de "etologia". Um corpo identitário, seja ele linguístico ou de outra natureza, seja ele singular ou coletivo, é uma combinação entre longitudes (conjunto de relaçóes de repouso ou de movimento, entre partículas não formadas) 
e latitudes (estados intensivos, afetos entrecruzados, forças anónimas em interseçáo). Tal como nos confirma Deleuze, no conjunto de latitudes e de longitudes, "o plano de imanência ou de consistência, sempre variável, e que não cessa de ser retocado, composto, recomposto pelos indivíduos e pelas coletividades" (DELEUZE, 2003, p. 171).

Nada de gestas históricas ou ficçóes soberanistas. Muito menos narrativas coloniais. Ainda menos apelos saudosistas a um referencial de solidez identitária. Apenas e só a língua à solta: filosofia ou literatura, no domínio rigoroso da leitura como resposta ao texto excedente: aqui ao leme sou mais do que eu!

\section{Escólio 2}

Repitamos, num último ímpeto, a citação de Llansol:

É minha convicção que as figuras (que, no meu texto, são muitas vezes figuras históricas do passado e, enquanto tais, culturalmente identificáveis) vêm do futuro (LLANSOL, 2000, p. 201).

A dita "identificação cultural" é, a partir daqui, assimétrica e heteronómica, não permitindo, talvez, a estabilização ou cristalização de qualquer identidade cultural. Figuras históricas não são, então, personagens, nem elementos localizáveis, mas elementos oferecidos ao acolhimento da leitura, num espaço literário sem fronteiras. Perde-se a "cultura", a "identidade", a "identidade cultural" das fórmulas que raptam o movimento e o devir em nome de uma fossilizaçáo essencialista, direta. É que, como afirma Derrida:

[...] o próprio de uma cultura é não ser idêntica a si mesma. Não o não ter identidade, mas o não poder identificar-se, dizer "eu" ou "nós", de não poder assumir a forma do sujeito senão na não-identidade a si ou, se preferirem, na diferença consigo. Não há cultura ou identidade cultural sem esta diferença consigo (DERRIDA, 1995, p. 96).

Toda a identidade vive fendida, cindida, interrompida com o que a desidentifica (sou mais do que eu, aqui ao leme), alimentada da diferença que a póe à vela. Razáo pela qual uma ética, desde logo investida pelo registo sem pacificação de uma alteridade absoluta, é motivo simultâneo de uma poética, quando uma identidade, uma cultura, uma língua são alcances de permanente convite à criaçáo, à performatividade e ao que chega a exceder 
a própria performatividade: o imperativo de fazer nascer língua, da língua e na língua. Um dos mais importantes desafios do pensamento que se escreveu e entreteceu em português está nesta marca identitária, neste registo claro, mas táo pouco óbvio de habitar poeticamente um mundo que, no espaço do poema, nunca se deixou localizar. Língua à solta!

\section{Consideraçóes finais}

Numa expressão tão notável quanto provocadora, José Gil brindanos com uma conclusão expressivamente desadequada de uma abordagem histórica e cronológica de tempo, que a invalidaria totalmente: "Fernando Pessoa leu Deleuze" (GIL, 1987, p. 71).

Essa leitura ficcionada, literariamente argumentada, enquadrase no que Eduardo Prado Coelho entendeu como "terceiro paradigma nos estudos pessoanos" (COELHO, 2003, p. 375-381): após o furor da pluralização (por vezes da patologizaçáo) heteronímica, após um segundo paradigma de priorizaçáo do texto, mas ainda marcado pelo peso existencial de uma identidade de crise, este terceiro paradigma lê Pessoa no tom de uma poética de intensidades - "a literatura como produção de um deviroutro que é ao mesmo tempo um devir-si-próprio" (COELHO, 2003, p. 380). Precisamente a deveniência que, como movimento filosófico-literário de travessia - disciplinar, identitária, cultural... - convoca talvez todo o Pessoa, todo o Deleuze, todo o Espinosa em Pessoa ou Deleuze e que sustenta, certamente, o excesso de si, "o mais de que Eu", a alteridade como inscrição perturbadora, titubeante, da identidade como cristalização egóide e solipsista. Na verdade, literária ou filosoficamente, aqui ao leme sou mais do que Eu...

Talvez, aqui também, o desígnio deleuziano se cruze com a viagem pessoana, para dizer que sempre o texto desenha uma outra cultura, no avesso de uma rígida concreção cultural que tudo monumentaliza. E só a energia desejante do texto - literatura e filosofia, literatura ou filosofia confere alcance ao cultivo de uma sempre outra e necessária identidade: o cultivo da língua como identidade. 


\section{Referências}

BLANCHOT, Maurice. L'Entretien infini. Paris: Gallimard, 1969. . L'Espace littéraire. Paris: Gallimard, 1998.

. Chroniques littéraires du Journal des Débats. avril 1941/août 1944. Paris: Gallimard, 2007.

. Le "discours philosophique". In: La condition critique. Articles 1945-1998. Paris: Gallimard, 2010. p. 332-337.

CAMPOS, Álvaro. Ode Marítima. In: Poesia. Lisboa: Assírio \& Alvim, 2002. p. 107-142.

CARVALHO, Joaquim. Prefácio a Ética. In: ESPINOSA, Bento de. Ética. Demonstrada à maneira dos geómetras. Tradução J. Carvalho. Coimbra: Atlântida. p. VII-CXLVI.

COELHO, Eduardo Prado. A noite do mundo. Lisboa: INCM, 2003.

ESPINOSA, Bento de. Ética. Demonstrada à maneira dos geómetras. Tradução J. Carvalho. Coimbra: Atlântida, 1960.

DELEUZE, Gilles. Qu'est-ce que la philosophie?. Paris: Ed. de Minuit, 1991. 1997.

. Crítica e clínica. Tradução P. Pelbart. Rio de Janeiro: Editora 34, Spinoza. Philosophie pratique. Paris: Éditions de Minuit, 2003.

DELEUZE, Gilles, GUATTARI, Félix. Kafka. Para uma literatura menor. Tradução R. Godinho. Lísboa: Assírio \& Alvim, 2003.

DERRIDA, Jacques. Khôra. Paris: Galilée, 1993.

. O outro cabo. Tradução F. Bernardo. Coimbra: A Mar Arte, 1995. Il me faudra errer tout seul. In: Chaque fois unique, la fin

du monde. Paris: Galilée, 2003. p. 235-238.

GIL, José. Fernando Pessoa ou a Metafísica das sensaçóes. Tradução M. Serras Pereira e A. Faria. Lisboa: Relógio d’Água, 1987. 
GIL, José, CATROGA, Fernando. O ensaísmo trágico de Eduardo Lourenço. Lisboa: Relógio d'Água, 1996.

LLANSOL, Maria Gabriela. Inquérito às quatro confidências. Lisboa: Relógio d'Água, 1996.

. Onde vais, Drama-Poesia?. Lisboa: Relógio d’Água, 2000.

LOURENÇO, Eduardo. Ocasionais I. Lisboa: Regra do jogo, 1984.

. Pessoa revisitado. Lisboa: Gradiva, 2000.

. O lugar do anjo. Ensaios pessoanos. Lisboa: Gradiva, 2004.

MARTINS, Fernando Cabral. Mensagem. In: MARTINS, Fernando Cabral (Ed.). Dicionário de Fernando Pessoa e do Modernismo Português. Lisboa: Caminho, 2008. p. 456-458.

PELLEJERO, Eduardo. A postulaçáo da realidade. Filosofia, literatura, política. Lisboa: Vendaval, 2009.

PESSOA, Fernando. A Mensagem. Lisboa: Ática, 1967.

PITA, António Pedro. O aprendiz do mundo e outros fantasmas. Coimbra: Pé de página, 2007.

RIMBAUD, Arthur. Oeuvres complètes. Correspondance. Paris: Ed. Bouquins, 1992. 